\title{
Management of iatrogenic bile duct injuries: Multiple logistic regression analysis of predictive factors affecting morbidity and mortality
}

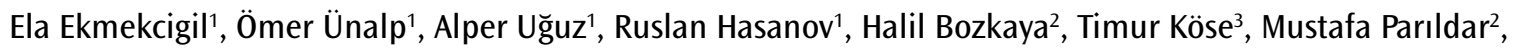
Ömer Özütemiz', Ahmet Çoker

ABSTRACT Objective: latrogenic bile duct injuries remain a challenge for the surgeons to overcome. The predictive factors affecting morbidity and mortality are important for determining the best management modality.

Material and Methods: The patients who referred to Ege University Faculty of Medicine after laparoscopy associated iatrogenic bile duct injury are grouped according to Strasberg-Bismuth classification system. The type and number of prior attempts, concomitant complications, and treatment modalities are analyzed using the SPSS version 18 (IBM, Chicago, IL, USA). The variables with $\mathrm{p}<0.10$ were considered for univariate analysis and then evaluated for predictive factors by forward Logistic Regression method using multiple logistic regression analysis.

Results: According to the analysis of 105 patients who were referred during 2004-2014, the type and number of prior attempts are considered predictive factors in sepsis. In multiple logistic regression analysis, abscess formation, concomitant vascular injury, and serum bilirubin level are significantly effective in predicting mortality.

Conclusion: The management of iatrogenic bile duct injuries should be carefully planned with a multidisciplinary approach. The predictive factors affecting morbidity and mortality are important in determining the best modality for managing iatrogenic bile duct injuries. Abscess formation, vascular injury, and serum bilirubin level are the potential risk factors. Therefore, we can strongly recommend immediate assessment of patients for prompt diagnosis and referring to an HPB center, to avoid further injuries.

Cite this paper as:

Ekmekcigil E, Ünalp 0̈, Uğuz

A, Hasanov R, Bozkaya H,

Köse I, et al. Management of iatrogenic bile duct injuries: Multiple logistic regression analysis of predictive factors affecting morbidity and mortality Turk J Surg 2018; 34(4): 264-270.

'Department of General Surgery, Ege University University School of Medicine, Izmir, Turkey ${ }^{2}$ Department of Interventional Radiology, Ege University University School of Medicine, İzmir, Turkey

${ }^{3}$ Department of Biostatistics and Medical Informatics, Ege University University School of Medicine, İzmir, Turkey

${ }^{4}$ Department of

Gastroenterology, Ege University University School of Medicine, İzmir, Turkey

This study was presented at the $11^{\text {th }}$ E-AHPBA congree in Manchester 21-24 August 2015, United Kingdom.

\section{Corresponding Author}

Ela Ekmekcigil

e-mail: eekmekcigil@gmail.com

Received: 25.10 .2017

Accepted: 30.11 .2017

Available Online Date: 28.08.2018

(C) Copyright 2018

by Turkish Surgical Association

Available online at

turkjsurg.com
Keywords: Bile duct injury, laparoscopy, predictive factors

\section{INTRODUCTION}

latrogenic bile duct injuries (IBDI) are important and serious complications that develop during laparoscopic cholecystectomy. Currently, more than $75 \%$ of cholecystectomies are performed laparoscopically and the frequency of IBDI is observed between $0.3 \%$ and $1.4 \%$ (1-6).

The prognosis of the injury has a broad spectrum. The clinical process that is observed with mild symptoms may lead to an increase in morbidity in which the survival expectancy decreases and the quality of life deteriorates $(7,8)$. What determine the prognosis in IBDI are the predictive factors that are effective on perioperative morbidity and mortality (9). The experience of the surgeon, advanced age and male gender, the presence of biliary duct anomalies, and local findings accompanied by severe inflammation and fibrosis are the risk factors known to cause IBDI $(10,11)$. The introduction of effective factors on the injury process will guide the surgeons in determining a distinguished treatment method. The aim of our study is to make a contribution to the optimum treatment approach in this regard by presenting effective risk factors on morbidity and mortality.

\section{MATERIAL AND METHODS}

In the Department of General Surgery, Ege University, Faculty of Medicine where the study was conducted; an average of 200 hepatopancreatobiliary patients including liver transplants, tumor resections and reconstructions are performed each year. The study was performed retrospectively with 105 patients who were transferred to our clinic as a tertiary center from multiple centers due to IBDI which developed during laparoscopic cholecystectomy between 2004 and 2014. Our study has been carried out in accordance with the Helsinki declaration.

\section{Obtaining the Data}

The patients' data were reached through the computer-registry system with hospital data-base. Data base was established on the basis of demographic data, initial symptoms, surgical interventions applied in patients prior to the admission to our center after injury, level and type of injury, accompanying complications, and perioperative outcomes obtained with the treatment methods that were applied at the tertiary center. 


\section{Patient Groups}

Injuries following the interventions in biliary tract (such as ERCP, PTC), injuries caused by trauma and malignant disease, blunt/penetrant injuries, and injuries caused by hepatectomy/ gastrectomy were not included in our study group. The patients undergoing laparoscopic cholecystectomy due to cholelithiasis were included in the study.

Patients were divided into three groups based on the number of interventions applied at the external center and on the appropriate treatment method chosen afterwards.

Group 1: Patients transferred to our clinic with the diagnosis of bile duct injury after laparoscopic cholecystectomy.

Group 2: Patients who were transferred to our clinic after surgical intervention in an external center for repair due to bile duct injury.

Group 3: Patients who were transferred to our clinic due to bile duct injury and treated with endoscopic and percutaneous methods.

Surgical methods were performed in the patients of the first group for therapeutic purposes in our clinic. Patients in the second group are the patients who were transferred after one or more surgical interventions for the purpose of repair and who were reoperated for treatment. The third group consisted of patients in whom non-surgical techniques (ERCP, PTC) were performed for treatment (Table 1).

\section{Clinical Features}

Findings that enabled the surgeon to notice the condition of injury in the postoperative period were analyzed through physical examination features and by grouping the data obtained from the imaging methods.

Parameters were established with gender characteristics, age-average and age groups ( $\leq 60,>60 \mathrm{y})$, serum bilirubin values and bilirubin scoring index $(<2 \mathrm{mg} / \mathrm{dL}, 2-10 \mathrm{mg} / \mathrm{dL},>10$ $\mathrm{mg} / \mathrm{dL}$ ). The effect of complication development (abscess development, hepatic and vascular injury, intestinal organ injury) on the prognosis was analyzed in the postoperative treatment period. Sepsis status was identified in the presence of clinical and microbiological infection and analyzed in patients with systemic inflammatory response syndrome (SIRS) criteria (12).

Surgical methods applied by the hepatobiliary surgeon for the purpose of repair before and after the transfer were analyzed and evaluated in terms of the effect on prognosis in the postoperative period.

\section{Classification}

The cases were classified according to the injury type and anatomic location on the basis of the Strasberg - Bismuth classification system (13). The prognostic effect of the level of injury was evaluated and the data used in the statistical analysis were grouped. Groups were formed as minor injuries (type A and type D), as major (types E1 and E2) and as complicated major injuries (type E3, type E4 and type E5).

The patients who were examined in terms of vital function findings and single / multiple organ failure were assessed with the Clavien - Dindo scoring system in order to determine the severity of complications according to postoperative treatment plan (14).

\section{Surgical Treatment}

The operation methods we preferred in our clinic for repair after the transfer of the patients and the methods performed in the external center before the transfer were analyzed in order to provide homogeneous analysis in the statistical evaluation by creating the same groups.

Non-surgical methods (such as PTC, ERCP) were primarily used for therapeutic purposes in minor type injuries in which main biliary duct continuity is mostly protected. In case of failure; T-tube placement with choledochotomy was preferred in limited injuries in the lateral surface of the duct in the distal part of the main hepatic duct (type D). In major injuries; in cases with proximal location and in which hepatic junction is preserved (type E1-E2), Roux-en-Y hepaticojejunostomy was performed. Roux-en-Y hepaticojejunostomy was performed to maintain the continuity of bilio-enteric tract in more proximal injuries (type E3-type E4-type E5) in which the integrity of main hepatic duct junction deteriorated. However, if there was a distance bigger than $1 \mathrm{~cm}$ between the mouths of injured hepatic duct, the ducts were made ready for anastomosis by bringing them together with sutures on the same plane using the 'double barrel technique'. In the case of complicated injuries in which the hilar sheath integrity deteriorated, hepaticojejunostomy was performed using the 'segment 3 approach'.

The mouth of the hepatic duct to be anastomosed was prepared taking into account the principle that the injured hepatic duct mucosa should reach the proximal end, where it is sufficiently vascularized. Intestinal orifice prepared narrower than the diameter of hepatic duct on the antimesenteric face of jejunum with distance at 20th $\mathrm{cm}$ from ligamentum of Treitz.Hepatic duct mouth was anastomosed one by one using 4/0-5/0 absorbable monofilament suture material to establish an integrity with the jejunum mucosa without any tension on the line using end-to-side anastomosis technique, and routine use of biliary stent was not preferred in the cases.

\section{Statistical Analysis}

Clinical parameters generated by computer-based data recording system were analyzed using SPSS-PASW statistics version 18.0 for Windows (SPSS Inc.; Chicago, IL, USA). Numerical variables of the groups were compared with the Kruskal Wallis and Mann Whitney $U$ tests. The data were analyzed with Pearson $x 2$ test and Fisher's exact test in univariate analysis. Nonparametric factors were calculated with Spearman's correlation coefficient test. In the statistical analysis, $\mathrm{p}<0.05$ was considered significant. The data accepted as significant in univariate analysis were taken into multiple logistic regression analysis with forward LR method. A $p$ value of $<0.10$ was accepted as significant in the selection of the risk factors whose efficacy would be assessed with multiple logistic regression analysis.

\section{RESULTS}

Among the 105 patients, the ratio of female/male was $83 / 22$ in terms of gender distribution. There were 30 patients over 
Table 1. Group of patients and clinical features

\begin{tabular}{|c|c|c|c|c|}
\hline \multicolumn{2}{|l|}{$\begin{array}{l}\text { Characteristics of } \\
105 \text { patients: }\end{array}$} & \multirow{2}{*}{$\begin{array}{c}\text { Group A: } \mathbf{n}(\%): \\
\text { (Primary referral) } \\
37(78.7)\end{array}$} & \multirow{2}{*}{$\begin{array}{c}\text { Group B: } \mathrm{n}(\%): \\
\text { (Secondary referral) } \\
25(78.1)\end{array}$} & \multirow{2}{*}{$\begin{array}{c}\text { Group C: } \mathbf{n}(\%): \\
\text { (interventional Treatment) } \\
21(80.8)\end{array}$} \\
\hline Gender & Female & & & \\
\hline & Male & $10(21.3)$ & $7(21.9)$ & $5(19.2)$ \\
\hline \multirow[t]{2}{*}{ Age (years) } & $<60$ & $33(70.2)$ & $23(71.9)$ & $19(73.1)$ \\
\hline & $>60$ & $14(29.8)$ & $9(28.1)$ & $7(26.9)$ \\
\hline \multirow[t]{3}{*}{ Blood Biluribin level (mg/dL) } & $<2$ & $25(54.3)$ & $12(38.7)$ & $25(96.2)$ \\
\hline & $2-10$ & $18(39.1)$ & $13(41.9)$ & $1(3.8)$ \\
\hline & $>10$ & $3(6.5)$ & $6(19.3)$ & $0(0)$ \\
\hline \multicolumn{2}{|l|}{ Mean value $(\mathrm{mg} / \mathrm{dL})$} & 3.4 & 5.75 & 1.09 \\
\hline \multicolumn{5}{|l|}{ İnitial procedure(s) } \\
\hline \multicolumn{2}{|l|}{ Lap. Cholecystectomy: } & $47(100)$ & - & $23(88.5)$ \\
\hline \multicolumn{2}{|c|}{ Conversion +/- Choledochotomy+T-tube: } & - & $23(71.9)$ & $2(7.7)$ \\
\hline \multicolumn{2}{|l|}{ Hepaticojejunostomy: } & - & $3(9.4)$ & $1(3.8)$ \\
\hline \multicolumn{2}{|c|}{ HJ.+Hepatectomy/Vascular/Intestinal repair: } & - & $6(18.8)$ & - \\
\hline \multicolumn{5}{|l|}{ Repair procedure(s) } \\
\hline \multicolumn{2}{|c|}{ Interventional\&medical treatment*: } & - & $4(12.5)$ & $26(100)$ \\
\hline \multicolumn{2}{|c|}{ Conversion + /- Choledochotomy+T-tube: } & $10(21.3)$ & $1(3.1)$ & - \\
\hline \multicolumn{2}{|l|}{ Hepaticojejunostomy: } & $30(63.8)$ & $22(68.8)$ & - \\
\hline \multicolumn{2}{|c|}{ HJ.+Hepatectomy/Vascular/Intestinal repair: } & $7(14.9)$ & $5(15.6)$ & - \\
\hline
\end{tabular}

* ERCP: Endoscopic Retrograde Cholangiopancreatography; PTC: Percutaneous Transhepatic Cholangiography; HJ: Hepaticojejunostomy

Table 2. Predictive effect of the injury level according to Strasberg-Bismuth classification on the development of mortality and sepsis

\begin{tabular}{|c|c|c|c|c|}
\hline \multirow[b]{2}{*}{ Level of Injury: } & \multicolumn{2}{|c|}{ Mortality } & \multicolumn{2}{|c|}{ Sepsis } \\
\hline & RR: & \%95 Cl: & RR: & \%95 Cl: \\
\hline Type A-D* Type E1-E2 & $\begin{array}{l}2.81 \\
\text { (NS) }\end{array}$ & $\begin{array}{l}0.24-32.6 \\
\text { (NS) }\end{array}$ & 6.0 & $1.45-24.9$ \\
\hline Type E3-E4-E5 & 8.86 & $1.03-76.06$ & 6.78 & $1.74-26.43$ \\
\hline
\end{tabular}

*Reference group

*RR: Relative Risk; 95\% Cl: 95\% Confidence Interval; NS: Nonspecific

the age of 60 with an average age of 46.2 years (range 20-78 years) (Table 1).

While, in Group 1, there were forty-seven patients (47, 45\%) who were transferred to our clinic with the diagnosis of injury after laparoscopic cholecystectomy applied in an external center, there were thirty-two patients $(32,31 \%)$ who underwent surgery before the transfer to our clinic in Group 2. There were twenty-six patients $(26,24 \%)$ treated with non-surgical (ERCP, PTC) methods for minor injuries in group 3. While the mortality rate in 105 patients was $9.5 \%$ (10 patients), the rate of sepsis development was $23.8 \%$ (25 patients).

\section{Univariate Analysis of Demographic Findings}

Age groups were grouped as below and over 60 years. When the reference group was under 60 years old, there was an increased risk of mortality in patients over 60 years of age ( $p<0.05$, RR: 4.43, 95\% Cl: 1.15-17.0). However, no difference was observed between male and female patients in terms of

\section{Univariate Analysis of Serum Bilirubin Values}

It was observed that the mean serum bilirubin level was 3.0 $\mathrm{mg} / \mathrm{dL}$ and biluribin level was an independent risk factor for sepsis development $(p<0.05)$. Statistical analysis performed with Mann Whitney $U$ test showed that while the median bilirubin level was $3.48 \mathrm{mg} / \mathrm{dL}(0.42-25 \mathrm{mg} / \mathrm{dL})$ in the sepsis group, the median value was $1.33 \mathrm{mg} / \mathrm{dL}(0.1-19)(p<0.001)$ in the non-sepsis group.

In the grouping that was made according to the bilirubin scoring index, the group with serum bilirubin level $<2 \mathrm{mg} / \mathrm{dL}$ was compared as a reference with the other groups. There was a significant risk increase in the group with $2-10 \mathrm{mg} / \mathrm{dL}$ serum bilirubin level in terms of mortality (RR: $14.78 \% 95 \% \mathrm{Cl}: 1.73-$ 123.3) and in terms of sepsis (RR: $6.07 \% 95 \% \mathrm{Cl}$ : 2.21-16.6).

\section{Univariate Analysis of Injury Level}

Minor injuries were compared with major injury groups as reference. There was a significant mortality risk increase in the group with complicated major injuries (type E1-E2-E3) (RR: 8.86\% 95\% Cl: 1.03-76.06). It was observed that the level of injury caused a significant increase in the risk of sepsis development (RR: 6.0 95\% Cl: 1.45-24.9 in type E1-E2-E5 injuries; RR: 6.78 95\% Cl: 1.74-26.43) (Table 2).

\section{Univariate Analysis of Previous Surgical Interventions}

After the injury, the effect of surgical methods performed before transfer of patients was evaluated for determining the prognosis after injury. There was a significant increase in the risk of sepsis (RR: $2.86 \%, 95 \% \mathrm{Cl}: 1.01-8.11$ ) in patients in whom conventional cholecystectomy was preferred or in whom cholecystectomy and choledochotomy - T-tube were performed 
Table 3. Predictive effect of the post-injury surgical methods applied at the external center on sepsis development and its relation with the frequency of vascular injuries

\begin{tabular}{|c|c|c|c|c|}
\hline \multirow[b]{2}{*}{ Method of Surgery: } & \multicolumn{2}{|c|}{ Sepsis } & \multicolumn{2}{|c|}{ Frequency of Vascular Injury } \\
\hline & RR: & 95\% Cl: & Rate: & $\%:$ \\
\hline Conventional cholecystectomy & 2.86 & $1.01-8.11$ & $5 / 25$ & $20 \%$ \\
\hline \multicolumn{5}{|l|}{ \pm Choledochotomy T-tube placement: } \\
\hline Hepaticojejunostomy & 1.69 & $0.16-17.85$ (NS) & $1 / 4$ & $25 \%$ \\
\hline Hepaticojejunostomy \pm Hepatic Injury & 10.18 & $1.66-62.6$ & $2 / 6$ & $33 \%$ \\
\hline \pm Vascular Injury & & & & \\
\hline \pm Intestinal Injury & & & & \\
\hline
\end{tabular}

*RR: Relative Risk; 95\% Cl: 95\% Confidence Interval; NS: Nonspecific

Table 4. Calculation of the risk coefficient for mortality and sepsis development by comparing the repair methods applied by the HPB surgeon in the Tertiary center with those treated by interventional methods

\begin{tabular}{|c|c|c|c|c|c|}
\hline \multirow[b]{2}{*}{ Method of Repair: } & & \multicolumn{2}{|c|}{ Mortality } & \multicolumn{2}{|c|}{ Sepsis } \\
\hline & & RR: & $95 \% \mathrm{Cl}:$ & RR: & $95 \% \mathrm{Cl}:$ \\
\hline Interventional Treatment & Conventional Cholecystectomy & 6.44 (NS) & $0.52-79.6$ & 2.0 (NS) & $0.28-14$ \\
\hline \multirow[t]{3}{*}{ Methods (ERCP-PTC)* } & \pm Choledochotomy T-tube placement : & & & & \\
\hline & Hepaticojejunostomy & 1.77 (NS) & $0.17-17.8$ & 3.25 (NS) & $0.84-12.5$ \\
\hline & $\begin{array}{l}\text { Hepaticojejunostomy } \pm \text { Hepatic Injury } \\
\pm \text { Vascular Injury } \\
\pm \text { Intestinal Injury }\end{array}$ & 14.5 & $1.42-148$ & 12.6 & $2.40-65.9$ \\
\hline
\end{tabular}

*Reference group, ERCP: Endoscopic Retrograde Cholangiopancreatography, PTC: Percutaneous Transhepatic Cholangiography ${ }^{*}$ RR: Relative Risk; $95 \%$ Cl: 95\% Confidence Interval; NS: Nonspecific

due to injury. Hepaticojejunostomy $(\mathrm{HJ})$ was performed in 10 of 105 patients after injury by the primary surgeon, but there was a significant increase in the risk of sepsis (RR: 10.1, 95\% Cl: 1.66-62.6) with accompanying injuries (hepatic injury, intestinal injury, vascular injury) in 6 of them (Table 3 ).

Thirty-two patients who were in group 2 and underwent multiple surgical interventions prior to the transfer to the EUFM general surgery clinic were re-operated by hepatobiliary surgeon. The number of previous surgical interventions was also analyzed in terms of risk increase and it was observed that the increase in the number of interventions applied was an effective predictor of sepsis development ( $>1$ intervention RR: 3\% 95\% Cl: 1.11-8.05). In 61 cases (58\%) referred with drainage catheter, there was no significant relationship between the presence of catheter and the development of mortality and sepsis $(p>0.05)$.

\section{Univariate Analysis of Surgical Methods Performed by Hepatobiliary Surgeon}

The effect of surgical approaches applied to the patients who were admitted to our clinic on the development of mortality and sepsis was analyzed. It was observed that the most preferred method of repair was hepaticojejunostomy $(\mathrm{HJ})$ (64 patients, 85.3\%). The patients treated with non-surgical methods (ERCP-PTC) (group 3) were accepted as the reference group and compared with the surgical methods applied by hepatobiliary surgeon. As a result of the analysis, it was observed that there was no risk increase in terms of the mortality and sepsis development (RR: $1.77 \% 95 \% \mathrm{Cl}$ : 0.17-17.8). However, in the presence of comorbid complications (hepatic-intestinalvascular injuries), there was an increase in risk in terms of mortality and sepsis development (RR: 14.5 95\% Cl: 1.42-148.5) (Table 4).

\section{Factors Affecting Hospitalization Period}

While the mean hospitalization period was 19.7 days, the longest hospitalization period was 24.5 days in group 2. It was revealed that there was no statistically significant difference among the three groups in terms of hospitalization duration ( $p>0.05$ ). It was observed that the development of biloma, abscess, biliary fistula and biliary stenosis did not statistically affect the hospitalization period ( $p>0.05$ ). The analysis that was made using Spearman's correlation coefficient showed that the time until the transfer of the patients to the tertiary center ( $r: 0.221 \mathrm{p}: 0.0028)$ after the laparoscopic cholecystectomy, and the number of applied percutaneous drainage ( $r: 0.430$ $\mathrm{p}<0.001)$ affected the hospitalization duration. However, accompanying complications (hepatic-intestinal-vascular injuries) were observed not to be statistically significant $(p>0.05)$.

\section{Univariate Analysis of Clinical Findings and Complications}

Twenty-seven of the 105 patients $(27,25.7 \%)$ were diagnosed during laparoscopic cholecystectomy. There were thirty-nine patients $(39,37.1 \%)$ who had the symptoms of abdominal pain on admission to our clinic, only 10 patients $(10,9.5 \%)$ with jaundice findings and two patients $(2,1.9 \%)$ with gastrointestinal hemorrhage. Among the parameters formed as a result of the analysis, it was observed that abdominal pain was the risk factor for the development of sepsis (RR: 5.72 95\% Cl: 1.25-26.24). 
When the accompanying complications were evaluated; it was observed that there were thirty-five patients $(35,33 \%)$ who had abscess formation, ten patients $(10,42.8 \%)$ with intestinal injuries and 17 patients $(17,16 \%)$ with vascular injuries. In the result of the risk analysis; abscess formation (RR: 3.73 95\% Cl: 1.43-9.7), intestinal injury (RR: 3.79\% 95\% Cl: 1-14.45) and vascular injury (RR: $14.495 \% \mathrm{Cl}: 4.29-48.25)$ were independent predictors in terms of sepsis and mortality. It was also observed through radiological methods that there was a significant risk of sepsis development in patients with biliary stenosis (RR: $3.73,95 \%$ Cl: 1.44-9.69) and biliary fistula (RR: 13.90, 95\% Cl: 1.78-108.43).

\section{Clavien-Dindo Classification System}

When the severity of complications was assessed with the Clavien - Dindo scoring system, the risk of sepsis development was also observed to have increased in relation to classification (RR: 6.44 95\% Cl: 2.86-14.51).

\section{Multiple Logistic Regression Analysis of the Factors effective} on Sepsis and Mortality Development

Among all independent predictors, the Clavien-Dindo classification system was not included in the analysis in order to provide the analysis of the most effective factors. The efficiency of the variables was revealed by calculating the corrected coefficients (CC).

It was observed that the most powerful predictors of sepsis were abscess development (CC: 6.74 95\% Cl: 1.21-37.60), accompanying vascular injury (CC: $29.4195 \% \mathrm{Cl}: 4.15-208.07$ ) and serum bilirubin level (CC: 4.25 95\% Cl: 1.034 -17.47).

When the factors were evaluated in terms of mortality, abscess development (CC: 38.25 95\% Cl: 2.61-558.8), accompanying vascular injury (CC: $17.595 \% \mathrm{Cl}: 1.45-211.8$ ) and serum bilirubin level (CC: $23.695 \% \mathrm{Cl}: 1.58$ - 352.6) were found to be significant predictors (Table 6).

Table 5. Univariate analysis of risk factors in sepsis development

\begin{tabular}{|lcc|}
\hline Univariate Analysis of Predictive Factors: & RR: & $\mathbf{9 5 \% ~ C l : ~}$ \\
\hline Abdominal Pain & 5.72 & $1.25-26.24$ \\
\hline Biliary Fistula & 13.90 & $1.78-108.43$ \\
\hline Abscess formation & 3.73 & $1.43-9.7$ \\
\hline Intestinal Injury & 3.79 & $1-14.45$ \\
\hline Vascular Injury & 14.4 & $4.29-48.25$ \\
\hline
\end{tabular}

RR: relative risk; $95 \% \mathrm{Cl}$ : 95\% confidence interval

\section{DISCUSSION}

Bile duct injuries are the complications that cause unexpected results for surgeons and negatively affect their occupational life. Likewise, they cause extremely hard situations for the repairing surgeon from a technical point of view. Even in the case of successful repair, it leaves a negative effect on the quality of life of the patients. While young populations frequently expect a quality of life postoperatively, it leads to consequences which may require intensive care support and result in mortality, which are difficult for the patients and relatives to understand, and difficult for us, the surgeons, to explain.

In bile duct injuries which have a distinctive importance among all postcholecystectomy complications, the first step is provided by the surgeon's awareness. We can define awareness as the particular importance that is given to the possibility of injury in patients with acute or chronic inflammation findings during operation, and in potential situations such as adhesion of infundibulum to the cystic duct, difficult dissection of the cystic duct, failure to reveal the anatomy, the presence of large stone in the Hartmann's pouch, or short cystic duct. Approximately $85 \%$ of IBDI is not diagnosed during primary iatrogenic surgery. According to the literature, the rate of diagnosis during operation is $15-30 \%(15,16)$. In our study, the rate of the patients diagnosed during the operation and referred to our clinic is $25.7 \%$. The most common symptom in the postoperative period was abdominal pain $(37.1 \%)$ and there was a significant relation with the development of sepsis in the course of prognosis. However, it was observed that there was no risk increase in patients in whom drainage was placed into the abdomen and referred due to the suspicion of injury. Abdominal pain, high fever, findings of abdominal distension suggesting biliary leakage in the postoperative period, and the presence of excess drainage with biliary characteristics in the patient in whom drainage was placed due to intraoperative suspicion are the clues that allow the surgeon to quickly recognize the condition of injury.

In our study, the risk of sepsis development was observed to increase even in patients in whom cholecystectomy +/- choledochotomy T-tube drainage was performed by the primary surgeon for the purpose of repairing. It was observed that, among the preferred methods, hepaticojejunostomy was performed in few cases, and that the risk of mortality and sepsis did not increase as long as there was no accompanying complication, but as seen in table 3 , the risk of vascular injury increased along with the progress of the surgical technique applied for repair. While Buell and Koffron published in their study that hepatic artery injury occurred in patients who had postcholecystectomy bile duct injury and in whom

Table 6. Scheme of the predictive factors that are observed in the final model through multiple logistic regression analysis

\begin{tabular}{|c|c|c|c|c|c|c|c|c|}
\hline \multirow[b]{2}{*}{ Risk Coefficients of Predictive Factors: } & \multicolumn{4}{|c|}{ Mortality } & \multicolumn{4}{|c|}{ Sepsis } \\
\hline & RR: & $95 \% \mathrm{Cl}:$ & CO: & $95 \% \mathrm{Cl}:$ & RR: & $95 \% \mathrm{Cl}:$ & CO: & 95\% Cl: \\
\hline Vascular Injury & 11.18 & $2.7-45.9$ & 17.5 & $1.45-211.8$ & 14.4 & $4.29-48.25$ & 29.4 & $4.1-208$ \\
\hline Abscess formation & 5.42 & $1.3-22.48$ & 38.25 & $2.61-558.8$ & 3.73 & $1.43-9.7$ & 6.74 & $1.2-37.6$ \\
\hline Serum Bilirubin Level & 14.7 & $1.77-123.39$ & 23.6 & $1.58-352.62$ & 6.071 & $2.21-16.66$ & 4.25 & $1.03-17.4$ \\
\hline
\end{tabular}

RR: relative risk; $95 \% \mathrm{Cl}$ : 95\% Confidence Interval; CO: Corrected Odds 
the primary treatment management failed $(17,18)$, it was observed in our study that repeated interventions ( $>1$ trial: RR: $3 \mathrm{Cl}: 1.11-8.05)$ for the purpose of repair before the transfer to tertiary center increased the risk of sepsis in the postoperative period. Stewart \& Way showed that the success rate of repair interventions performed by the primary surgeon who conducted cholecystectomy was $17 \%$, but it reached $94 \%$ when applied by an experienced hepatobiliary surgeon (1921). In univariate analysis of complications; intestinal injuries were revealed as the causative predictor (Table 5) in 10 of 105 patients and with multiple logistic regression analysis abscess formation was also shown as one of the strongest predictors (Table 6). In the literature; while major complications occurred after reconstructive surgery in $21 \%$ of the patients who underwent intervention for repair at the center where they were transferred from, the complication rate was observed to be $6 \%$ in the patients transferred without intervention (22). The fact that combined biliary and vascular injuries are associated with serious complications such as hepatic necrosis and abscess development after reconstructive surgery and that they increase the likelihood of late recurrent stenosis $(23,24)$ suggests that patients who are to undergo complicated hepatobiliary surgery should be transferred to tertiary centers (25-28).

In the result of multiple logistic regression analysis, we observed that the value of serum bilirubin was a significant predictor in order to obtain good postoperative outcomes and to take necessary precautions against single/multiple organ failure in patients scheduled for repair surgery. In the analysis performed with the serum bilirubin values of the patients at the admission; when the bilirubin level was lower than $2 \mathrm{mg} / \mathrm{dl}$, it did not lead to a risk increase; however, when it reached the range of $2-10 \mathrm{mg} / \mathrm{dL}$, the risk of sepsis development (Corrected Odds CO: $4.25 \mathrm{Cl}: 1.034$ - 17.47) and mortality (CO: $17.5 \mathrm{Cl}: 1.45$ - 211.8) significantly increased; but, similarly, there was no increase in the patients with the values higher than $10 \mathrm{mg} / \mathrm{dL}$. The time until the transfer of the patients to the tertiary center and the increase in the number of percutaneous drainage, which are among the factors prolonging the hospitalization period, caused an increase in morbidity in patients whose transfer was delayed. At this point, the evaluation of the patients in a tertiary center where gastroenterologists, interventional radiologists and HPB surgeons are available is important in terms of prognosis $(29,30)$.

When we evaluated the mortality rates, the average rate was $9.5 \%$ for all patients, it was observed to be $7.1 \%$ for the patients transferred after single intervention, and $14.2 \%$ for the patients receiving multiple interventions.

\section{CONCLUSION}

latrogenic bile duct injuries are complications in which the treatment management should be determined through a careful planning with a multidisciplinary approach. Quick decisions taken with missing data can cause to worsen the current picture. The best treatment approach should be provided in the light of predictive factors that are effective on mortality and morbidity. The development of abscess, vascular injury and the increase in the serum bilirubin level are potential risk factors affecting the prognosis. With the recognition of the in- jury and avoiding the complications with recurrent interventions, the arrangement of treatment approaches in the light of predictive factors that are effective on prognosis will increase the survival expectancy.

Ethics Committee Approval: The authors declared that the research was conducted according to the principles of the World Medical Association Declaration of Helsinki "Ethical Principles for Medical Research Involving Human Subjects.

Informed Consent: Informed consent was not received due to the retrospective nature of the study.

\section{Peer-review: Externally peer-reviewed.}

Author Contributions: Concept A.Ç.; Design - A.Ç., E.E.; Supervision A.Ç., Ö.Ö.; Resource - Ö.Ü., A.U.; Materials - E.E., R.H.; Data Collection and/or Processing - E.E., H.B.; Analysis and/or Interpretation - E.E., T.K., A.Ç.; Literature Search - Ö.Ü., M.P.; Writing Manuscript - E.E.; Critical Reviews - A.Ç., M.P., Ö.Ö.; Other - M.S.

Acknowledgements: Special thanks to Prof. Dr. Murat Sözbilen for his great effort in performing surgeries.

Conflict of Interest: The authors have no conflicts of interest to declare.

Financial Disclosure: The authors declared that this study has received no financial support.

\section{REFERENCES}

1. Fletcher DR, Hobbs MS, Tan P, Valinsky LJ, Hockey RL, Pikora TJ, et al. Complications of cholecystectomy: risks of the laparoscopic approach and protective effects of operative cholangiography: a population-based study. Ann Surg 1999; 229: 449-457. [CrossRef]

2. Calvete J, Sabater L, Camps B, Verdû A, Gomez-Portilla A, Martin J, et al. Bile duct injury during laparoscopic cholecystectomy: myth or reality of the learning curve? SurgEndosc 2000; 14: 608-611. [CrossRef]

3. MacFadyen BV Jr, Vecchio R, Ricardo AE, Mathis CR. Bile duct injury after laparoscopic cholecystectomy. The United States experience. Surg Endosc 1998; 12: 315-321. [CrossRef]

4. Go PM, Schol F, Gouma DJ. Laparoscopic cholecystectomy in the Netherlands. Br J Surg 1993; 80: 1180-1183. [CrossRef]

5. Gouma DJ, Go PM. Bile duct injury during laparoscopic and conventional cholecystectomy. J Am Coll Surg 1994; 178: 229-233.

6. Richardson MC, Bell G, Fullarton GM. Incidence and nature of bile duct injuries following laparoscopic cholecystectomy: an audit of 5913 cases. Br J Surg 1996; 83: 1365-1360. [CrossRef]

7. Flum DR, Cheadle A, Prela C, Dellinger EP, Chan L. Bile duct injury during cholecystec- tomy and survival in medicare beneficiaries. JAMA 2003; 290: 2168-2173. [CrossRef]

8. Boerma D, Rauws EA, Keulemans YC, Bergman JJ, Obertop H, Huibregtse K, et al. Impaired quality of life 5 years after bile duct injury during laparoscopic cholecystectomy: a prospective analysis. Ann Surg 2001; 234: 750-757. [CrossRef]

9. Savader $S J$, Lillemoe $K D$, Prescott $C A$, Winick $A B$, Venbrux $A C$, Lund GB, et al. Laparoscopic cholecystectomy-related bile duct injuries: a health and financial disaster. Ann Surg 1997; 225: 268273. [CrossRef]

10. Goor DA, Ebert PA. Anomalies of the biliary tree. Report of a repair of an accessory bile duct and review of the literature. Arch Surg 1972; 104: 302-309. [CrossRef]

11. Strasberg SM, Hertl M, Soper NJ. An analysis of the problem of biliary injury during laparoscopic cholecystectomy. J Am Coll Surg 1995; 180: 101-125. 
12. Fry DE. Sepsis Syndrome. Am Surg 2000; 66: 126-132.

13. Strasberg SM, Hertl M, Soper NJ. An analysis of the problem of biliary injury during laparoscopic cholecystectomy. J Am Coll Surg 1995; 180: 101-125.

14. Dindo D, Demartines N, Clavien PA. Classification of surgical complications: a new proposal with evaluation in a cohort of 6336 patients and results of a survey. Ann Surg 2004; 240: 205-213. [CrossRef]

15. De wilt LT, Rauws EA, Gouma DJ. Surgical management of iatrogenic bile duct injury. Scand J Gastroenterology Suppl 1999; 230: 89-94.

16. Gouma DJ, Obertop H. Management of bile duct injuries: treatment and long-term results. Dig Surg 2002; 19: 117-122. [CrossRef]

17. Koffron A, Ferrario M, Parsons W, Nemcek A, Saker M, Abecassis $M$. Failed primary management of iatrogenic biliary injury: incidence and significance of concomitant hepatic arterial disruption. Surg 2001; 130: 722-731. [CrossRef]

18. Buell JF, Cronin DC, Funaki B, Koffron A, Yoshida A, Lo A, et al. Devastating and fatal complications associated with combined vascular and bile duct injuries during cholecystectomy. Arch Surg 2002; 137: 703-710. [CrossRef]

19. Johnson AG, Lyon IM, Blumgart LH. Stricture of common hepatic duct after right hepatic lobectomy treated by Longmire's operation. J R Soc Med 1979; 72: 136-139. [CrossRef]

20. Stewart L, Way LW. Bile duct injuries during laparoscopic cholecystectomy: factors that influence the results of treatment. Arch Surg 2003; 130: 1123-1128. [CrossRef]

21. Stewart L, Way LW. Laparoscopic bile duct injuries: timing of surgical repair does not influence success rate. A multivariate analysis of factors influencing surgical outcomes. HPB (Oxford) 2009; 11: 516-522. [CrossRef]
22. de Reuver PR, Grossmann I, Busch OR, Obertop H, van Gulik TM, Gouma DJ. Referral Pattern and Timing of Repair Are Risk Factors for Complications After Reconstructive Surgery for Bile Duct Injury. Ann Surg 2007; 245: 763-770. [CrossRef]

23. Gupta N, Solomon H, Fairchild R, Kaminski DL. Management and outcome of patients with combined bile duct and hepatic artery injuries. Arch Surg 1998; 133: 176-181. [CrossRef]

24. Schmidt SC, Langrehr JM, Hintze RE, Neuhaus P. Long-term results and risk factors influencing outcome of major bile duct injuries following cholecystectomy. Br J Surg 2005; 92: 76-82. [CrossRef]

25. Flum DR, Cheadle A, Prela C, Dellinger EP, Chan L. Bile duct injury during cholecystectomy and survival in medicare beneficiaries. JAMA 2003; 290: 2168-2173. [CrossRef]

26. Carroll BJ, Birth M, Phillips EH. Common bile duct injuries during laparoscopic cholecystectomy that result in litigation. Surg Endosc 1998; 12: 310-313. [CrossRef]

27. Gordon TA, Burleyson GP, Tielsch JM, Cameron JL. The effects of regionalization on cost and outcome for one general high-risk surgical procedure. Ann Surg 1995; 221: 43-49. [CrossRef]

28. Savader $S J$, Lillemoe $K D$, Prescott $C A$, Winick $A B$, Venbrux $A C$, Lund GB, et al. Laparoscopic cholecystectomy related bile duct injuries: a health and financial disaster. Ann Surg 1997; 225: 268273. [CrossRef]

29. Sicklick JK, Camp MS, Lillemoe KD, Melton GB, Yeo CJ, Campbell $K A$, et al. Surgical management of bile duct injuries sustained during laparoscopic cholecystectomy: perioperative results in 200 patients. Ann Surg 2005; 241: 786-792. [CrossRef]

30. Fischer CP, Fahy BN, Aloia TA, Bass BL, Gaber AO, Ghobrial RM. Timing of referral impacts surgical outcomes in patients undergoing repair of bile duct injuries. HPB (Oxford) 2009; 11: 32-37. [CrossRef] 